\title{
Interpersonal flexibility, Type A individuals, and the impostor phenomenon
}

\author{
KAIRA M. HAYES and STEPHEN F. DAVIS \\ Emporia State University, Emporia, Kansas
}

\begin{abstract}
The present study investigated the relationships between interpersonal flexibility, Type A behavior, and impostor characteristics in college students. Although no significant relationship was found to exist between interpersonal flexibility and Type A behavior, interpersonal flexibility and impostor characteristics were negatively related for both men and women. Although Type A and impostor characteristics were negatively related for men, they were positively related for women.
\end{abstract}

Interpersonal behavior, defined as behavior related in some fashion to another human being, has been called the most important dimension of personality (Leary, 1957). Individuals whose interpersonal responses are stable but flexible are able to make a better or more effective adjustment to changing environmental/social demands. According to Paulhus and Martin (1988), there are two dimensions within the general context of interpersonal flexibility. First, individuals who are interpersonally flexible must have a variety of responses in their behavioral repertoire. Additionally, they must be able to choose the most appropriate and effective behavioral response for their current situation.

Because androgyny and self-monitoring involve the two dimensions of interpersonal flexibility (Paulhus \& Martin, 1988; Spiro \& Weitz, 1990), these traits should be indicative of interpersonal flexibility. Androgynous people possess both feminine and masculine traits and tend to be more sensitive to situational demands than do nonandrogynous people (Bem, 1975). Since individuals who are not androgynous behave only in a manner congruent with their gender, they have a more limited range of behavioral responses. Thus, androgynous individuals are thought to be more interpersonally flexible than nonandrogynous people (Paulhus \& Martin, 1988).

Snyder (1974) describes high self-monitoring individuals as being very sensitive to their self-presentation and adapting their behavior according to situational demands. Conversely, low self-monitoring individuals exhibit a more stable pattern of behaviors across situations. Therefore, it can be reasoned that high self-monitoring individuals are more interpersonally flexible than are low selfmonitoring individuals.

Unfortunately, measurement of androgyny and/or selfmonitoring does not adequately evaluate the dimensions of interpersonal flexibility. Hence, the Battery of Interpersonal Capabilities (BIC) was designed to measure interpersonal flexibility (Paulhus \& Martin, 1987). Because it assesses the respondent's perceived capability of exhibit-

Requests for reprints should be addressed to S. F. Davis, Department of Psychology, Emporia State University, Emporia, KS 66801-5087. ing 16 different personality traits, if required by the situation, it is felt that the BIC is superior to the other, more unidimensional accounts (Paulhus \& Martin, 1987). The purpose of the present study was to relate scores on the BIC to other relevant personality variables.

Since its identification by Friedman and Rosenman (1959), a plethora of research has been conducted on the Type A behavior pattern. Generally, this research indicates that individuals exhibiting the Type A behavior pattern tend to be work-oriented, competitive, impatient, hostile, and determined to achieve as much as possible in as short an amount of time as possible, whereas Type B individuals are considered to exhibit the opposite characteristics (Ivancevich \& Matteson, 1988). Relevant to a consideration of interpersonal flexibility, it has been shown that Type A individuals are more interpersonally dominant (Yarnold \& Grimm, 1989) and higher in selfmonitoring (Furnham, 1989) than are Type B individuals. Thus, it is predictable that a positive relationship exists between Type A behavior and interpersonal flexibility.

The term impostor phenomenon was developed to "designate an internal experience of intellectual phoniness" (Clance \& O'Toole, 1988, p. 51). Because victims of the impostor phenomenon are successful and mask their feelings of insecurity and doubt, it could be hypothesized that they would exhibit proficient interpersonal flexibility. However, since the interpersonal flexibility measure employs capability ratings, "impostors" may, in fact, score low in interpersonal flexibility because of their intense, genuine feelings of self doubt regarding their true capabilities. The present study sought to assess these predictions.

\section{METHOD}

\footnotetext{
Subjects

Eighty-three students (24 men, 59 women) enrolled at a regional state university located in the Midwest volunteered to serve as subjects. The mean age of the men was 22.13 years (range $=18-41$ years); the mean age of the women was 21.31 years (range $=17-50$ ).

Testing Instruments

The 80-item BIC (Paulhus \& Martin, 1987) was used to assess interpersonal flexibility. The modified Jenkins Activity Survey (JAS; Krantz, Glass, \& Snyder, 1974), a 21-item questionnaire, was used to measure
} 
Type A behavior. The Impostor Test (Clance, 1985), which consists of 20 Likert-type items, was used to measure impostor characteristics. The three testing instruments and a demographic sheet that requested gender, age, classification, and major were combined to form a selfadministering booklet.

\section{Procedure}

All testing took place during a regularly scheduled class session. The subjects first were given an informed consent form that was explained by the experimenter. Following completion and retrieval of the informed consent forms, the questionnaire booklets were distributed. Although no time limit was imposed, all subjects completed the questionnaire booklets within $20 \mathrm{~min}$.

\section{RESULTS}

Separate product-moment correlation coefficients involving the BIC, JAS, and the Impostor Test were calculated for the men and for the women. These correlations are shown in Tables 1 and 2, respectively.

Additionally, the JAS, BIC, and Impostor scores of the men and women were compared. The results of these analyses indicated that the men and women did not differ reliably with respect to interpersonal flexibility [BIC, $t(81)=2.03, p>.08$ ] and Type A characteristics [JAS, $t(81)=1.12, p=.53$ ]. However, women had significantly higher scores on the impostor test $[t(81)=2.56$, $p<.02]$. The latter result replicates several previous reports (e.g., Clance, 1985; Clance \& O’Toole, 1988).

\section{DISCUSSION}

Contrary to our initial prediction, the present data failed to yield a significant relationship between interpersonal flexibility and the Type A behavior pattern. This finding reflects the contradictory nature of the research regarding Type $A$ individuals and their behavior in social situations. For example, Straub, Grunberg, Street, and Singer (1990) and Yarnold and Grimm (1989) reported that Type A subjects were more dominant than Type B subjects in social situations. Because both studies placed their subjects in competitive situations, the dominance displayed by the Type $\mathrm{A}$ individuals may have been the most appropriate and adaptable reaction. It could be inferred from these data that the Type A indi-

Table 1

Correlations Between Interpersonal Flexibility (BIC), Type A Behavior Pattern (Type A), and the Impostor Phenomenon in Men

\begin{tabular}{lccc}
\hline Questionnaire & BIC & JAS & Impostor \\
\hline BIC & & -.09 & $-.48 \dagger$ \\
JAS & & & $.40^{*}$ \\
Impostor & & & \\
\hline
\end{tabular}

Note-BIC $=$ Battery of Interpersonal Capabilities, JAS $=$ Jenkins Activity Survey. ${ }^{*} p<.05 . \quad t p<.02$.

Table 2

Correlations Between Interpersonal Flexibility (BIC), Type A Behavior Pattern (Type A), and the Impostor Phenomenon in Women

\begin{tabular}{lccc}
\hline Questionnaire & BIC & Type A & Impostor \\
\hline BIC & & -.04 & $-.52 \dagger$ \\
Type A & & $-.39^{*}$ \\
Impostor & & \\
\hline $\begin{array}{l}\text { Note-BIC }=\text { Battery } \\
\dagger p<.01 .\end{array}$
\end{tabular}

viduals in these situations were more interpersonally flexible than their Type B counterparts.

However, it has also been reported that Type A individuals are more apt to engage in interpersonal communication patterns that increase conflict (Bruch, McCann, \& Harvey, 1991). Since behavior that elicits conflict is not likely to be viewed as the most appropriate and adaptable reaction for the situation, this evidence supports the view that Type As are less interpersonally flexible than Type Bs. Since the present research found no relationship between interpersonal flexibility and Type A characteristics, it is likely that a factor other than interpersonal flexibility was operating in the research reporting significant relationships between interpersonal dominance and Type A characteristics.

The significant negative relationship between interpersonal flexibility and the impostor phenomenon supports the prediction that as impostor feelings increase, capability ratings on the BIC would decrease. Because impostors feel that they are frauds and are not truly capable, in spite of all that they have achieved, they are unlikely to report having the capability to exhibit a variety of interpersonal abilities.

The gender difference found in the relationships between impostor scores and Type A characteristics is intriguing. As the Type A scores of the men increased, so did their impostor scores; the opposite pattern was shown by the women. At first glance, these results appear to contradict previous reports. For example, the Type A behavior pattern has been found to be positively correlated with psychosocial adjustment in men but not in women (Watkins et al., 1992). If heightened impostor feelings are indicative of poor psychosocial adjustment, the present research found that psychosocial adjustment and Type A characteristics are positively related in women but not in men.

However, these Type A impostor results may be better understood in light of data reported by Thompson, Grisanti, and Pleck (1985). These researchers found a positive correlation between acceptance of the traditional male role and approval of the Type A behavior pattern. Since many Type A characteristics (e.g., competitiveness, achievement striving, and need for recognition) are considered to be masculine, this relationship is understandable. Perhaps the male subjects in the present study felt pressured to endorse the Type A behavior patterns in order to appear masculine. If this endorsement is made at the expense of concealing one's true attitudes and emotions, then the self-perception of fraudulence could be enhanced. Under these conditions impostor scores might be expected to rise.

The positive relationship between impostor scores and the Type A behavior pattern is in accord with results reported by McGregor, Eveleigh, Syler, and Davis (1991) showing that Type As had a higher opinion of their intellectual abilities and academic achievements than did Type Bs. Since impostors are not likely to report high opinions of themselves, they would likely score low on the JAS. On the other hand, the present data and those reported by McGregor et al. contradict a report by Henley and Furnham (1989) suggesting that Type As are not as happy with themselves as are Type Bs. Clearly, future research is warranted to delineate the nature and causes of these inconsistencies.

\section{REFERENCES}

BEM, S. L. (1975). Sex role adaptability: One consequence of psychological androgyny. Journal of Personality \& Social Psychology, 31, 634-643.

Bruch, M. A., McCann, M., \& Harvey, C. (1991). Type A behavior and processing of social conflict information. Journal of Research in Personality, 25, 434-444.

Clance, P. R. (1985). The imposter phenomenon: Overcoming the fear that haunts your success. Atlanta: Peachtree.

Clance, P. R., \& O'Toole, M. A. (1988). The imposter phenomenon: An internal barrier to empowerment and achievement. Women \& Therapy, 6, 51-64.

Friedman, M., \& Rosenman, R. H. (1959). Association of specific overt behavior patterns with blood and cardiovascular findings. Journal of the American Medical Association, 169, 1286-1296.

Furnham, A. (1989). Personality correlates of self-monitoring: The relationship between extraversion, neuroticism, Type A behavior and Snyder's self-monitoring construct. Personality \& Individual Differences, 10, 35-42. 
Henley, S., \&urnham, A. (1989). The Type A behaviour pattern and self-evaluation. British Journal of Medical Psychology, 62, 51-59.

Ivancevich, J. M., \& Matteson, M. T. (1988). Type A behaviour and the healthy individual. British Journal of Medical Psychology, 61, 37-56.

Krantz, D. S., Glass, D. C., \& Snyder, M. L. (1974). Helplessness, stress level, and the coronary-prone behavior pattern. Journal of Experimental Social Psychology, 10, 284-300.

LEARY, T. (1957). Interpersonal diagnosis of personality. New York: Ronald Press.

McGregor, L., Eveleigh, M., Syler, J. C., \& Davis, S. F. (1991). Self-perception of personality characteristics and the Type A behavior pattern. Bulletin of the Psychonomic Society, 29, 320-322.

Paulhus, D. L., \& Martin, C. L. (1987). The structure of personality capabilities. Journal of Personality \& Social Psychology, 52, 354-365.

Paulhus, D. L., \& Martin, C. L. (1988). Functional flexibility: A new conception of interpersonal flexibility. Journal of Personality \& Social Psychology, 55, 88-101.
SNYDER, M. (1974). Self-monitoring of expressive behavior. Journal of Personality \& Social Psychology, 30, 526-537.

SPIRo, R. L., \& Weitz, B. A. (1990). Adaptive selling: Conceptualization, measurement, and nomological validity. Joumal of Marketing Research, 27, 61-69.

Straub, R. O., Grunberg, N. E., Street, S. W., Singer, J. E. (1990). Dominance: Another facet of Type A. Journal of Applied Social Psychology, 20, 1051-1062.

Thompson, E. H., Grisanti, C., \& Pleck, J. H. (1985). Attitudes toward the male role and their correlates. Sex Roles, 13, 413-427.

Watkins, P. L., Fisher, E. B., Schechtman, K. B., Southard, D. R., WARD, C. H., CARPENTER, L. (1992). Gender differences in Type A behavior and hostility within an organizational setting. Psychology \& Health, 6, 141-151.

YARNOLD, P. R., \& GRIMM, L. G. (1989). Interpersonal dominance of Type As and Bs during involved group discussions. Journal of Applied Social Psychology, 18, 787-795.

(Manuscript received April 9, 1993.) 